\title{
Effect of Zno Nanoparticles on Chlorophyll Content of Wheat Plants(Triticum Aestivum L.)
}

\author{
J. A. Bagawade, S. S. Jagtap
}

\begin{abstract}
Nanoparticles have achieved novel applications in biotechnology and agricultural industries. Nanoparticles on plants may cover a new insight to the ecosystems. There is a need for advance study of the possible effects of the nanoparticles on plant growth and development. In the present investigation, zinc oxide nanoparticles have been prepared by the simple chemical route and were authorized by $U V$-vis spectrophotometer and $X$-ray diffraction (XRD) analysis alongwith transmission electron microscope (TEM). The consequence of various concentrations of synthesized zinc oxide nanoparticles on wheat seeds (variety: lok-1) was studied by soaking approach and follow its effect on seedling growth of wheat (at 5 days). The seed germination, plant growth \& chlorophyll content characteristics were measured by using standard biophysical techniques and studied. Results showed enhancement in germination and growth characteristics in five days grown wheat seedlings for control upto thousand ppm. Above thousand ppm, the considerable drop off was observed in these parameters upto two thousand ppm. Also, the chlorophyll content in the control sample is greater than the samples treated with the various concentrations of zinc oxide nanoparticles. There was a noticeable effect that employing suitable concentration of $\mathrm{ZnO}$ nanoparticles could support the seed germination of wheat in contrast to untreated control.
\end{abstract} Growth

Keywords: Zinc oxide nanoparticles, Wheat, Chlorophyll,

\section{INTRODUCTION}

Nanotechnology is one of the rapidly developing discipline and revolutionary fields in science and technology and has found several applications in various areas such as electronics, cosmetics, pharmaceutics, textiles, crop production, protection and improvement, smart delivery systems of fertilizers, herbicides, pesticides, fertilizer and irrigation management, food and agricultural production etc. $[1,2]$. It has a promising potential to solve many of the agricultural-related problems with remarkable improvement. Effect of different nanoparticles on germination, growth characteristics, biomass and physiological activities, chlorophyll content has also been reported [3, 4]. A number of investigators have also reported the crucial role of zinc for plant yield and development [5-8]. Some Plant species, i.e. rape, corn, lettuce, radish, ryegrass, cucumber and wheat [8-10] are sensitive toward $\mathrm{ZnO}$ nanoparticles.

Revised Manuscript Received on April 25, 2020. *Correspondence Author

J. A. Bagawade*, Assistant Professor, Department of Physics, Vidya Pratishthan's Arts,Science and Commerce College, Vidyanagari, Baramati, Dist. Pune-413113 MS,India.Email: jbchimanpure10@gmail.com

S. S. Jagtap, Department of Physics, H. V. Desai College, Pune -02, MS, India.

(C) The Authors. Published by Blue Eyes Intelligence Engineering and Sciences Publication (BEIESP). This is an open access article under the CC BY-NC-ND license (http://creativecommons.org/licenses/by-nc-nd/4.0/)
Presence of $\mathrm{ZnO}$ nanoparticles in surrounding environment affects plant architecture, physiology and biochemistry $[10,11]$.It is important to examine their effects on the quality and productivity of the major cereal crop like wheat with almost $75 \%$ of its 600 million tons annual production used in food supply [12]. Thus, this growth depends upon concentrations of nanoparticles which may be different in different plants. However some few studies have been reported on investigating the potential of high concentration of nanoparticles in wheat growth. Our goal of the present study aimed to assess the effects of various concentrations of zinc oxide nanoparticles on germination, percentage, seedling growth and especially chlorophyll content in Wheat (Triticum aestivum L.).

\section{MATERIALS AND METHODS}

Basically, zinc oxide $(\mathrm{ZnO})$ NPs are prepared by using zinc chloride and sodium hydroxide as precursors (Aldrich 99\%). Zinc oxide nanoparticles were synthesized by dissolving $20 \mathrm{ml}$ of zinc chloride $(0.1 \mathrm{M}), 100 \mathrm{ml}$ of sodium hydroxide $(0.1 \mathrm{M} \mathrm{NaOH})$ and thioglycerol (TG )in methanol [13]. The synthesized TG capped zinc oxide NPs suspended in water were then used for treatment. The experimental treatments included five concentrations of nano $\mathrm{ZnO}$ (10000, 8000, 6000, 4000 and 2000 ppm) and untreated control. The healthy Wheat (Tritium Aestivum.) seeds (variety Lok-1 ) with uniform size were surface sterilized in 5\% sodium hypochloride solution for half an hour and then rinsed with distilled water for several times to remove excess of chemical. The treatment of nano $\mathrm{ZnO}$ to elected seeds was similar to our our previous paper and seeds soaked in distilled water were acted as control as reported earlier [10]. In this study, agar gel used as growing medium or a substrate to reduce the errors. The germination rate (\%) was calculated as the proportion of the germinated grains to total number of grains. The seedling surfacing was observed periodically, shoot, root length, and fresh weight (FW) were measured [10]. The numbers of seeds germinated of each sample after twenty four hours of sowing were measured. We used the germination parameters: Weighted germination index (WGI), Final percentage germination (GP) for each treatment was calculated after seven days. Similarly, Vigor index for each sample was calculated by using the Vigor index formula, Seedling vigor was computed based on the formula [14] After an incubation period of days, plumule and radical length of seedlings were measured using a ruler. The chlorophyll content in leaves was measured as an indicator of the plants photosynthetic performance.

Blue Eyes Intelligence Engineering 
Fresh 0.02 gm shoots of each sample were cut from seed and dissolved in $80 \%$ acetone solution. After 24 hours, absorption spectra were recorded for each chlorophyll solution by using UV-Visible spectroscopy.

Final chlorophyll contents chlorophyll-a, chlorophyll-b and total chlorophyll were estimated by using Arnob's formula. [15], $C_{a}=0.0127$ D663 - 0.00269 D645, $C_{b}=0.0229$-D645 0.00468-D663, and $\mathrm{C}_{\text {total }}=\mathrm{C}_{\mathrm{a}}+\mathrm{C}_{\mathrm{b}}=0.0202 \mathrm{D} 645+$ 0.00802D663[16]. Where, $\mathrm{C}_{\mathrm{a}}$ and $\mathrm{C}_{\mathrm{b}}$ are chlorophyll $\mathrm{a}$ and $\mathrm{b}$, respectively and $\mathrm{D}$ is density value at the respective wavelengths.

\section{RESULTS \& DISCUSSIONS}

The size and morphology of zinc oxide nanoparticles were examined using TEM and XRD. TEM revealed the presence of spherical monodispersed zinc oxide nanoparticles with 3-5nm size as reported in our previous study [13]. XRD analyses indicated single phase $\mathrm{ZnO}$ Wurtzite crystal structure. Particle size calculated from the XRD and that from the TEM is comparable to each other. [13]. In this study, we assessed the impact of zinc oxide nanoparticles on mainly responsive phases of plant progress, i.e. seed germination and seedling growth. Among wheat germination indices, seed germination rate was affected by practical treatments. The percentage seed germination decreased for various concentrations of nanoparticles as shown in Figure 1[10].

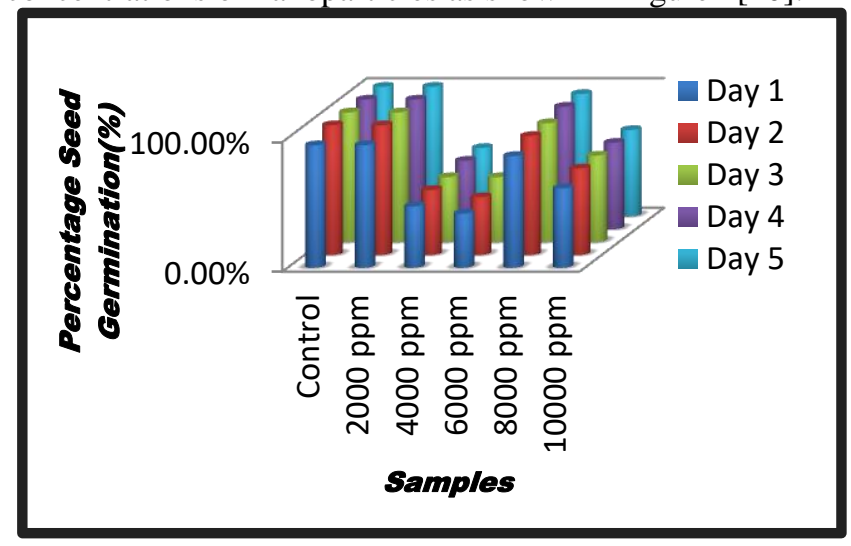

Fig. 1 Percentage Seed Germination

The seed germination was remained 100\% in 2000 pm. sample which was similar to control. However, the percentage seed germination of nanoparticles treated wheat seedlings was reduced as compared to control sample from $4000 \mathrm{ppm}$ to $10000 \mathrm{ppm}$ as except small increase at 8000 ppm shown in figure 1 . The growths of nanoparticle treated seedlings reduced with enhance in concentration and follow the similar trend as that of percentage seed germination (data not shown). The shoot length and root lengths are decreased with increase in concentrations of nanoparticles. However, no significant change was observed in number of secondary roots. Alike tendency was observed for shoot weight and root weights. Also, there is a decrease in vigor index in nanoparticles treated seedlings compared control [10]. The absorption spectra of chlorophyll are shown in figure 2 .

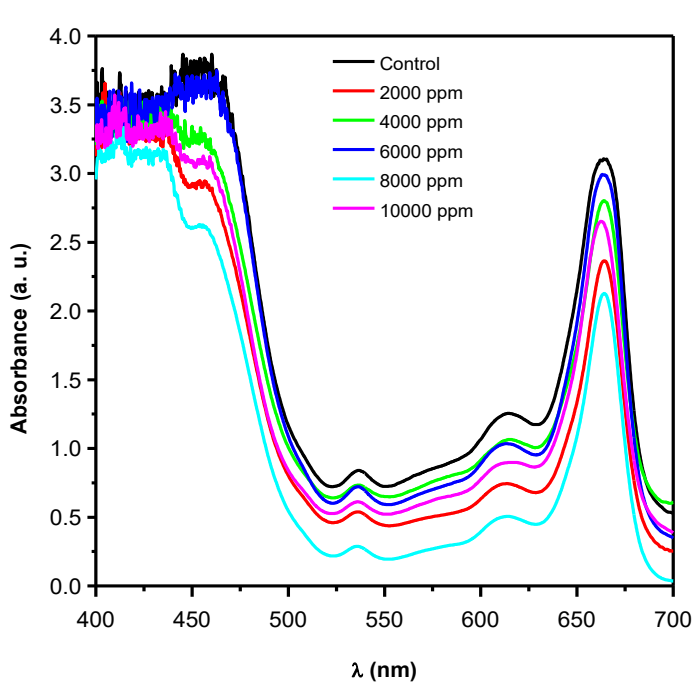

Fig. 2 Absorption Spectra of Chlorophyll

The chlorophyll contents viz., chlorophyll-a, chlorophyll-b and total chlorophyll were calculated from the absorption spectra by using Argon's formula. From figure 2, it is seen that the absorbance in control sample is higher than the samples treated with the different concentrations of $\mathrm{ZnO}$ NPs. Also, the chlorophyll content in the control sample is greater than the samples treated with the different concentrations of $\mathrm{ZnO}$ NPs as shown in table 1.

Table I Chlorophyll Content calculated by using Arnon's formula

\begin{tabular}{|c|c|c|c|}
\hline Samples & $\begin{array}{c}\mathrm{C}_{\mathrm{a}} \\
(\mathrm{mg} / \mathrm{l})\end{array}$ & $\begin{array}{c}\mathrm{C}_{\mathrm{b}} \\
(\mathrm{mg} / \mathrm{l})\end{array}$ & $\begin{array}{c}\mathrm{C}_{\text {total }} \\
(\mathrm{mg} / \mathrm{l})\end{array}$ \\
\hline Control & 34.87 & 26.11 & 60.98 \\
\hline $\begin{array}{c}2000 \\
\mathrm{ppm}\end{array}$ & 27.1 & 13.75 & 40.85 \\
\hline $\begin{array}{c}4000 \\
\mathrm{ppm}\end{array}$ & 31.56 & 20.58 & 52.14 \\
\hline $\begin{array}{c}6000 \\
\mathrm{ppm}\end{array}$ & 33.82 & 22.98 & 56.8 \\
\hline $\begin{array}{c}8000 \\
\mathrm{ppm}\end{array}$ & 24.68 & 9.3 & 33.98 \\
\hline $\begin{array}{c}10000 \\
\mathrm{ppm}\end{array}$ & 30.09 & 18.82 & 48.91 \\
\hline
\end{tabular}

All treatments prove that zinc oxide nanoparticles did not negatively affect wheat seed germination. A decrease in the root length has been detected with further increasing the concentration of zinc with longer soaking time tempting inhibition of root development. The toxicity of zinc oxide nanoparticles toward number of wheat roots and its root length is noticeable for different concentrations. Several previous studies showed that the zinc oxide nanoparticles increase plant development for different concentrations of zinc oxide nanoparticles.e.g. $400 \mathrm{ppm}$ and $1000 \mathrm{ppm}$ concentration give higher yield in peanut [17] ; 500 ppm and $1000 \mathrm{ppm}$ in soya bean [18]; $10 \mathrm{ppm}$ to $40 \mathrm{ppm}$ in onion,

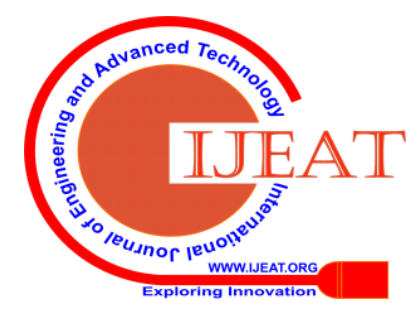


studied by Raskar et al. [19]; \& 1.5 ppm in chickpea, Uday Burman [20] reported that lesser applications of zinc oxide nanoparticles proved positive effect on seed germination. Also same results were obtained in radish, rape, corn, lettuce and cucumber to [8] and these results were consistent with Arnab Mukherjee [15] in green pea plants (Pisumsativum L.). Thus, the effect of nanoparticles on germination depends on concentrations of NPs and may vary from plants to plants. Seed germination is beginning of a physiological process that needs water imbibitions. The toxic effect is more uttered in the roots. Yang and Watts [21] reported the same results for alumina nanoparticles (nano- $\mathrm{Al}_{2} \mathrm{O}_{3}$ ). However, in our case, the toxicity of zinc oxide nanoparticles was found to be greater with respect to its concentration. This physical or chemical toxicity is due to the size, shape, chemical composition, surface energy of nanoparticles and mainly plant species.

\section{CONCLUSIONS}

In summary, zinc oxide nanoparticles affect responsive phases of wheat plant development ,the seed germination and growth characteristics \& chlorophyll content of wheat plant. The chlorophyll content in the control sample is greater than the samples treated with the different concentrations of $\mathrm{ZnO}$ NPs. Results of our previous and present study showed development in germination, growth \& chlorophyll content in 5 days grown wheat seedlings for control up to 1000 ppm and above $1000 \mathrm{ppm}$, the considerable decrease was observed in these factors upto $2000 \mathrm{ppm}$. In addition, for various concentrations of zinc oxide nanoparticles the root, dry matters shoot and seedling lengths were influenced in wheat plants. i.e. employing suitable concentration of zinc oxide NPs could support the seed germination of wheat in comparison to untreated control or else high concentrations had inhibitory or whichever effects on wheat. Further study should be carried out to determine impacts of zinc oxide nanoparticles on new agricultural crops as well.

\section{ACKNOWLEDGEMENT}

Authors are thankful to BCUD, SPPU authorities for providing financial assistance. (Research Proposal-No. 13SCI001943)

\section{REFERENCES}

1. Carmen IU.; Chithra P.; Huang Q.; Takhistov P.; Liu S.; Kokini JL.; Nanotechnology: a new frontier in food science. J.Food Technol. ,2003 ,57, pp. 24-29.

2. Pérez-de-Luque, A.; Rubiales, D. Nanotechnology for parasitic plant control. Pest Manage. Sci. 2009, 65 (5), pp. 540-545.

3. R. Raliya, P. Biswas and J. C. Tarafdar, "TiO2 nanoparticle biosynthesis and its physiological effect on mung bean (Vigna radiate L.)", Biotechnology Reports, Vol. 5, 2015; pp. 22-26.

4. M. R. Castiglione, L. Giorgetti, C. Geri andR. Cremonini, The effects of nano-TiO2 on seed germination, development and mitosis of root tip cells of Vicia narbonensis L. and Zea mays L", Journal of Nanoparticle Research, Vol. 13, No. 6,2011, pp. 2443-2449.

5. Kaya C. and D. Higgs., Response of Tomato (LycopersiconesculentumL.)Culture at Low Zinc. J.Scientific Horticulture.Vol. 93(2002): pp.. 53-64.

6. Pandey N.; G. C. Pathak ; C. P. Sharma ; Zinc is Critically Required for Pollen Function and Fertilization in Lentil.Journal of Trace Elements in Medicine and Biology. 2006,20, pp.89-96.

7. Cakmak I.; Enrichment of Cereal Grains with Zinc: Agronomic or Genetic Biofortification? Plant and Soil, 2008,302, pp. 1-17.

8. Lin D.; Xing B.; Phytotoxicity of Nanoparticles: Inhibition of Seed Germination And Root Growth. Environmental Pollution, 2007.150, pp. 243-250.

9. W. Du, Y. Sun, R. Ji, J. Zhu, J. Wu and H. Guo, TiO2 and $\mathrm{ZnO}$ nanoparticles negatively affect wheat growth and soil enzyme activities in agricultural soil. J. Environ. Monit. 2011, 13(4), pp. 822.

10. J.A.Bagawade, S.S.Jagtap 'Effect of zinc oxide nanoparticles on Germination and Growth characteristics in Wheat Plants', IJAERD Vol5(4),2018.pp 204-209.

11. Avinash CP, Sharda SS, Raghvendra SY. Application of $\mathrm{ZnO}$ nanoparticles in influencing the growth rate of Cicer arietinum. Journal of Experimental Nano Science. 2010; 5(6):1-12.

12. Khot L.R.; Sankaran S.; Maja JM.; Ehsani R.; Schuster W.; Applications of nanomaterials in agricultural production and crop protection: A review, J.Crop Protection,2012, 35, pp. 64-70.

13. Shriwas Ashtaputre; Aparna Deshpande; Sonali Marathe; M. E. Wankhede; J. Chimanpure; Renu Pasricha; J. Urban; S. K. Haram; S. W. Gosavi;S. K. Kulkarni; Pramana , Journal of Physics, 2005,165 (4), pp. 615. Synthesis \&analysis of $\mathrm{ZnO}$ and CdSe nanoparticles

14. Hruby M.; Cigler P.; Kuzel S.; Journal Plant Nutr. 2002,25, pp. 577-598.

15. Arnab Mukherjee; Lijuan Zhao; Jose Peralta-Videa; Jorge Gardea-Torresdey; stainable Nanotechnology Organization. 2013,10, pp. 1039.

16. Brown, P.H.,I.Cakmak, and Q.ZhangForms and Function of Zinc in Plants. In: Zinc in Soil and Plants,ed. A.D.Robson,.Dordrecht, the Netherlands: Kluwer Academic Publishers. .1993 pp.93-106

17. T. N. V. K. V. Prasad,P. Sudhakar,Y. Sreenivasulu,P. Latha,V. Munaswamy,K. Raja Reddy, Journal of Plant Nutrition, 2012,35(6),905-927.

18. M.H. Siddiqui; M.H. Al-Whaibi; Saudi J. Role of nano-SiO2 in germination of tomato (Lycopersicum esculentum seeds Mill.) Bio. Science, 2014, 21(1), pp. 13-17.

19. Laware S. L.; Raskar S.; Int.J.Curr.Microbiol.App.Sci (2014) ,3(7) 874-881, Influence of Zinc Oxide Nanoparticles on Growth, Flowering and Seed Productivity in Onion

20. Uday Burman; Mahesh Saini; Praveen- Kumar; Effect of zinc oxide nanoparticles on growth and antioxidant system of chickpea seedlings Journal of Toxicological \& Environmental Chemistry ,Volume 95, 2013 - Issue 4,pp.605-612.

21. Yang L. and Watts D.J. Particle surface characteristics may play an important role in phytotoxicity of alumina nanoparticles,Toxicology Letters, 2005,158(2): pp.122-132.

\section{AUTHORS PROFILE}
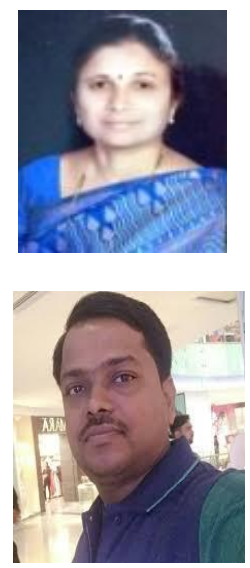

Mrs. Jayashri Bagawade, Assistant Professor, at Vidya Pratishthan's Arts, Science and Commerce College, Baramati, India. She received her Ph.D. in Physics, from SPPU,Pune. She published research papers in reputed national and international journals and conferences. Her current research interests are in the field of Material Science, Nanoscience and Nanotechnology, Biophysics, Energy studies etc

Mr. Sagar Shankar Jagtap, Assistant Professor, at H.V.Desai College, Pune, India. He received his Ph.D. in Physics, from SPPU, Pune. He published research papers in reputed national and international journals and conferences. His current research interests are in the field of Material Science, Biophysics, Nanoscience and Nanotechnology, etc.

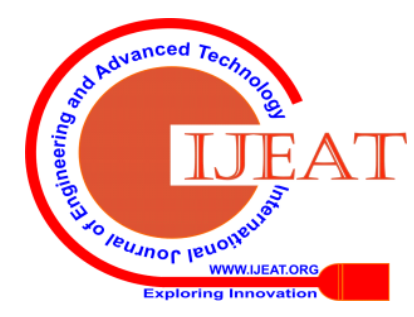

